\title{
Bipolar disorder and diabetes mellitus: evidence for disease-modifying effects and treatment implications
}

\author{
Ellen F. Charles ${ }^{1}$, Christophe G. Lambert ${ }^{2}$ and Berit Kerner $3,4^{*}$
}

\begin{abstract}
Background: Bipolar disorder refers to a group of chronic psychiatric disorders of mood and energy levels. While dramatic psychiatric symptoms dominate the acute phase of the diseases, the chronic course is often determined by an increasing burden of co-occurring medical conditions. High rates of diabetes mellitus in patients with bipolar disorder are particularly striking, yet unexplained. Treatment and lifestyle factors could play a significant role, and some studies also suggest shared pathophysiology and risk factors.
\end{abstract}

Objective: In this systematic literature review, we explored data around the relationship between bipolar disorder and diabetes mellitus in recently published population-based cohort studies with special focus on the elderly.

Methods: A systematic search in the PubMed database for the combined terms "bipolar disorder" AND "elderly" AND "diabetes" in papers published between January 2009 and December 2015 revealed 117 publications; 7 studies were large cohort studies, and therefore, were included in our review.

Results: We found that age- and gender- adjusted risk for diabetes mellitus was increased in patients with bipolar disorder and vice versa (odds ratio range between 1.7 and 3.2).

Discussion: Our results in large population-based cohort studies are consistent with the results of smaller studies and chart reviews. Even though it is likely that heterogeneous risk factors may play a role in diabetes mellitus and in bipolar disorder, growing evidence from cell culture experiments and animal studies suggests shared disease mechanisms. Furthermore, disease-modifying effects of bipolar disorder and diabetes mellitus on each other appear to be substantial, impacting both treatment response and outcomes.

Conclusions: The risk of diabetes mellitus in patients with bipolar disorder is increased. Our findings add to the growing literature on this topic. Increasing evidence for shared disease mechanisms suggests new disease models that could explain the results of our study. A better understanding of the complex relationship between bipolar disorder and diabetes mellitus could lead to novel therapeutic approaches and improved outcomes.

Keywords: Bipolar disorder, Diabetes, Epidemiology, Cohort studies, Pathophysiology, Evidence

\section{Background}

Bipolar disorder (BD) refers to a group of conditions that share the defining features of elated/euphoric or irritable mood accompanied by persistently increased activity or energy levels, also known as mania (American Psychiatric

\footnotetext{
*Correspondence: Berit.Kerner@uni-wh.de

${ }^{4}$ Fakultät für Gesundheit, Private Universität Witten/Herdecke,

Alfred-Herrhausen-Straße 50, 58448 Witten, Germany

Full list of author information is available at the end of the article
}

Association 2013). BD occurs worldwide with a lifetime prevalence of about $0.6 \%$ for BD-I and $0.4 \%$ for BD-II, with slightly higher rates reported in developed countries (Merikangas et al. 2007, 2011).

Evidence for an increase in chronic medical conditions in patients with BD has been described since the pretreatment era (Esquirol 1845; Swift 1907; Rennie 1942; Stenstedt 1952; Alvarez Ariza 2009). Several disorders are frequently diagnosed in patients with BD, including epilepsy, thyroid disorders, cardiovascular diseases, 
autoimmune-allergic disorders, and diabetes mellitus, especially in the elderly (Lala and Sajatovic 2012; Perugi et al. 2015). Since symptoms of these somatic disorders overlap with those of $\mathrm{BD}$, they could challenge the diagnostic process and delay treatment (Sajatovic and Chen 2011; Smith et al. 2013; Maina et al. 2013). Chronic medical conditions in patients with severe mental illness also lead to increased risk of frequent hospitalizations and re-hospitalizations (Davydow et al. 2015). While recent reviews of this topic have identified comorbid medical conditions in the elderly with $\mathrm{BD}$ as a growing public health problem (Depp and Jeste 2004; Vasudev and Thomas 2010; Dols et al. 2014; Sajatovic et al. 2015a), this patient population is often not well represented in clinical trials (Beers et al. 2014). However, case reports suggest that co-occurring medical conditions have a significant effect on the disease onset, the disease course, treatment response, and outcome (Sami et al. 2015). Diabetes mellitus appears to take center stage among these disorders.

Recent reports and one meta-analysis have suggested a relationship between $\mathrm{BD}$ and diabetes mellitus. However, these studies could not disentangle the effects of ethnicity, medication use and age, which could have potentially confounded the results (Vancampfort et al. 2015). Especially, the variability in the prevalence of diabetes mellitus in the background population has been rarely considered. Small sample sizes and restricted mean age range were the main limitations in most studies. In a systematic review, we have attempted to address some of these shortcomings. In contrast to previous studies, we have focused on large population-based cohort studies from diverse ethnic backgrounds with special attention to those studies that included the elderly. Then, we reviewed the evidence for shared disease mechanisms between BD and diabetes mellitus. Finally, we explored the evidence for disease-modifying effects and treatment implications.

\section{Methods}

Using the combined terms "bipolar disorder" AND "elderly" AND "diabetes", two independent researchers have carefully searched the PubMed database for large, observational cohort studies with retrospective, crosssectional, or prospective design published between January 2009 and December 2015. We found 117 papers; 7 studies were large cohort studies from diverse populations (Table 1), and therefore, were suitable for our review. Two reviewers independently selected the studies and extracted the data in duplicate according to predefined criteria and a study protocol that could be provided on request. Studies were included if they were population based, contain patients diagnosed with BD based on Diagnostic and Statistical Manual of Mental Disorders, 4th Edition (DSM-IV) or International Classification of Diseases (ICD) criteria, and also included patients diagnosed with diabetes mellitus. Excluded were studies that had excluded elderly patients, studies that were not population based and studies that did not mention the inclusion of patients with diabetes mellitus in addition to BD (Fig. 1). Since the number of the identified studies was too small and too diverse for meta-analysis, we refrained from a statistical analysis.

\section{Results \\ Bipolar disorder and diabetes mellitus: is there a connection?}

The results of the seven large population-based studies published between January 2009 and December 2015 provided strong evidence for a correlation between BD and diabetes mellitus (Table 1). When compared to the population background, odds ratios for diabetes mellitus in patient populations with BD were in the range of 1.7-3.2. Reciprocally, BD was more common among those with diabetes mellitus compared to the general population when adjusted for age and gender (Wändell et al. 2014). A nationwide, population-based longitudinal cohort study found that patients with BD, who had no diagnosis of diabetes mellitus at baseline, were more likely to begin anti-diabetic medications over the 10-year course of the study, even after controlling for gender, urbanization, and income (Bai et al. 2013). Across all ethnic and racial groups, females seem to have additional risk. Glucose and lipids were dysregulated at high rates in patients with BD, particularly in women over age 40 (Wysokinski et al. 2015), and obesity, a major risk factor for diabetes mellitus, was highly prevalent (Goldstein et al. 2011).

The results of these very large studies are consistent with the results of previous literature reviews covering smaller studies up to 2012, which found that diabetes mellitus occurs up to three times as often among individuals with $\mathrm{BD}$, as it does in the general population (Calkin et al. 2013; Janssen et al. 2015). However, some studies also indicated that metabolic dysfunctions in patients with $\mathrm{BD}$ are frequently underdiagnosed (Carliner et al. 2014; Konz et al. 2014).

\section{Discussion}

Bipolar disorder and diabetes mellitus: do these disorders share common disease mechanisms?

The results of our study suggest a relationship between $\mathrm{BD}$ and diabetes mellitus. Therefore, we reviewed the supporting evidence for shared disease mechanisms based on the broader literature.

A common explanation for the association between $\mathrm{BD}$ and diabetes mellitus focuses on the diabetogenic 


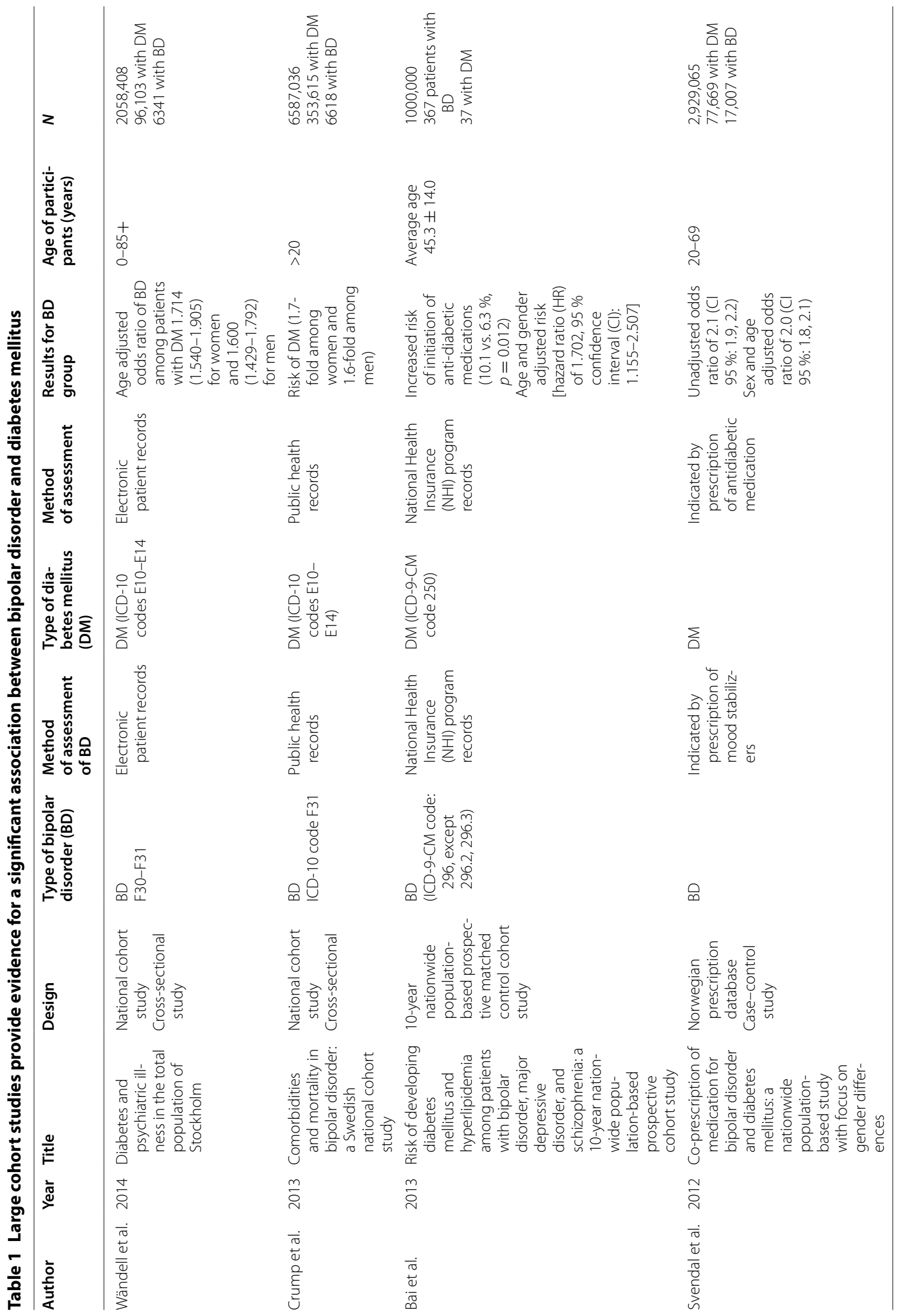




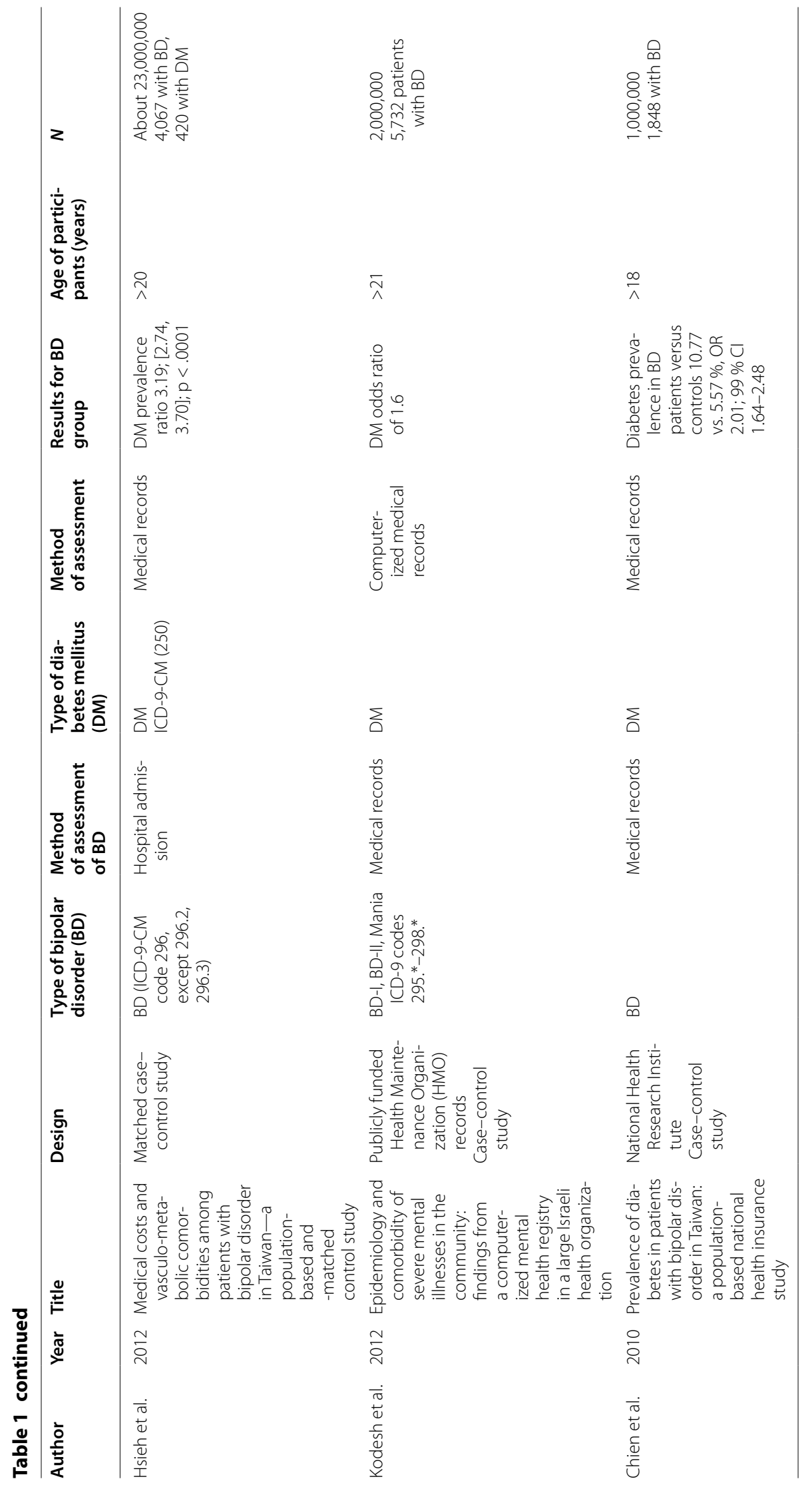




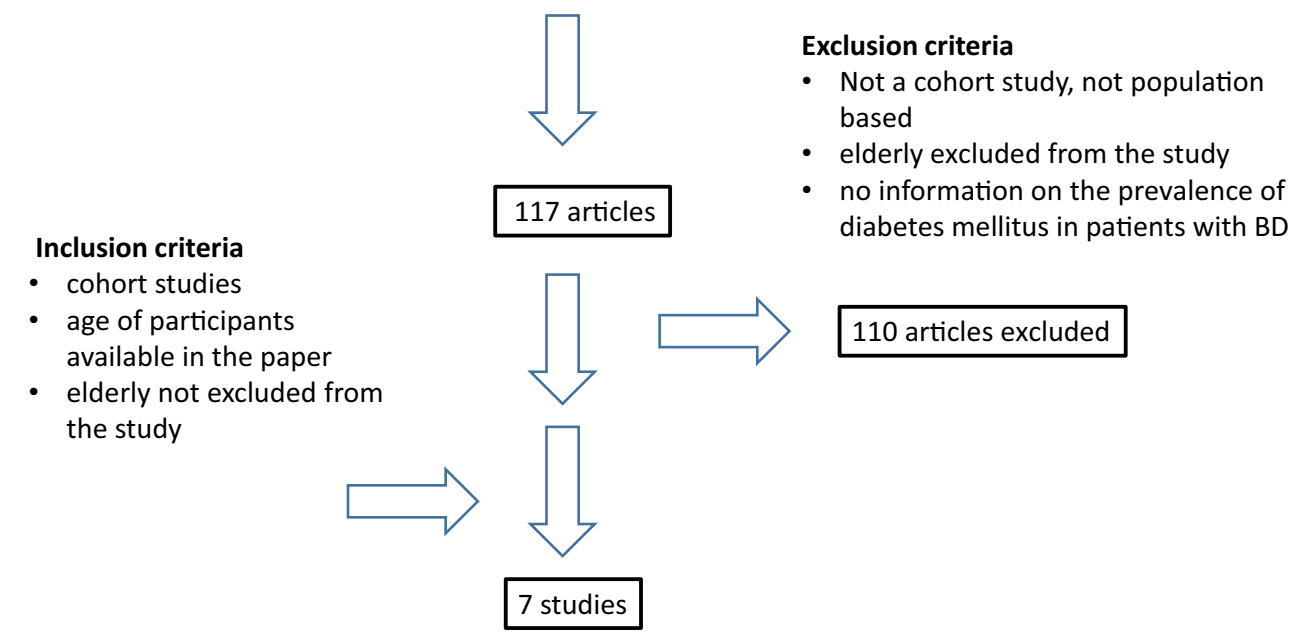

Fig. 1 Selection process for the inclusion in the systematic review

side effects of psychotropic medications, but evidence is also increasing for a medication-independent association (Foley et al. 2015). While diabetes mellitus in patients with BD has been associated with unintended medication effects (Correll et al. 2015), antipsychotics are more strongly linked to incident diabetes mellitus than other treatments, such as mood stabilizers and antidepressants. Among the antipsychotics, olanzapine and clozapine (both second generation antipsychotics) have been most strongly linked to diabetes mellitus, because they block insulin secretion as antagonists of acetylcholine muscarinic 3 receptors in the $\beta$-cells of the pancreas (Thakurathi and Henderson 2012; Weston-Green et al. 2013). A sedentary lifestyle has been claimed as another contributing factor to the increased risk of diabetes mellitus in patients with BD (Perseghin et al. 1996; Gomes et al. 2013; Janney et al. 2014; Conn et al. 2014). However, even after accounting for antipsychotic exposure and lifestyle factors, the higher incidence of diabetes mellitus among patients with BD remains unexplained, especially in treatment-naïve patients (Lilliker 1980; Cassidy et al. 1999; Regenold et al. 2002; Ruzickova et al. 2003; McIntyre et al. 2005; Maina et al. 2008; García-Rizo et al. 2014; Guha et al. 2014).

The observed association between $\mathrm{BD}$ and diabetes mellitus has inspired several hypotheses about shared disease mechanisms (Calkin et al. 2013). While some researchers have focused on dysregulations of the purine metabolism as a common link between energy homeostasis and neuro-regulation (Salvadore et al. 2010), others have proposed elevated cortisol levels related to imbalances in the hypothalamic-pituitary-adrenal axis, which consequently could result in obesity and derailment of the glucose metabolism (McElroy et al. 2004). A few researchers have hypothesized that insulin resistance in adipose tissue could be mediated by abnormalities in thyroid hormone receptor signaling pathways and gene regulation. Imbalances in thyroid hormones have long been suspected to be causally related to BD (Iwen et al. 2013). A new disease model hypothesizes that thyroid hormone receptor-associated protein 3 (Thrap3) could activate a diabetogenic gene cascade in adipose cells through interaction with cyclin-dependent kinase 5 (CDK5) leading subsequently to the phosphorylation of peroxisome proliferator-activated receptor $\gamma$ (PPAR $\gamma$ ) at Ser273 (Choi et al. 2014). An extension of this model included sleep abnormalities, which are frequently found in patients with psychiatric disorders, as a contributing factor to the manifestation of diabetes mellitus (Li et al. 2013). While thyroid hormone abnormalities have been convincingly linked to BD (Bauer et al. 2014), a causal link between thyroid abnormalities, diabetes mellitus, and mood symptoms continues to be a focus of intense investigations in cell culture and animal models (Wang 2013).

Increased insulin resistance is commonly considered an intermediate phenotype to the manifestation of diabetes mellitus. In patients with $\mathrm{BD}$, an alternative pathomechanism has been explored in the context of the metabolic syndrome, a combination of obesity, diabetes mellitus, dyslipidemia and hypertension. The metabolic syndrome is very common in the general population, 
but it occurs at even higher rates in patients with $\mathrm{BD}$ (Fagiolini et al. 2005). While insulin resistance was not increased in patients with BD and metabolic syndrome compared to age, gender, and body mass index (BMI)matched controls, patients with BD had a reduced capacity to utilize fat as an energy source. This abnormality could predispose BD patients to exacerbated weight gain and increased risk for diabetes mellitus and cardiovascular disease (Fleet-Michaliszyn et al. 2008).

Perhaps the most intriguing hypothesis linking BD and diabetes mellitus has focused on underlying immune dysfunctions paired with a chronic inflammatory state, which could confer risk for both BD and diabetes mellitus (Leboyer et al. 2012; Hamdani et al. 2013; Sharma et al. 2014; Rosenblat and McIntyre 2015; Kim et al. 2015). This argument is supported by findings of increased susceptibility to allergies and elevated pre-inflammatory markers in BD and in diabetes mellitus (Goldstein et al. 2009; Wang et al. 2013; Chen et al. 2014). Oxidative stress could also lead to cell damage and apoptosis in the pancreas and in the brain, suggesting shared environmental risk factors for $\mathrm{BD}$ and diabetes mellitus (Reininghaus et al. 2014; Wright et al. 2006; Chang and Chuang 2010). This disease mechanism has been convincingly demonstrated in rat pancreatic $\beta$-cells, in which increased $\beta$-cell apoptosis was initiated by endoplasmic reticulum (ER) stress, mediated by abnormal glycogen synthase kinase-3 $\beta$ (GSK-3 $\beta$ ) and caspase- 3 activity. Valproic acid inhibited GSK-3 $\beta$, which resulted in a cytoprotective effect. While this disease mechanism still awaits confirmation in patients with $\mathrm{BD}$, the striking results suggest abnormal GSK-3 $\beta$ activity as a common link between BD and diabetes mellitus supported by a potentially similar drug effect of valproic acid on GSK-3 $\beta$ in the pancreas and in the brain (Huang et al. 2014).

\section{Bipolar disorder and diabetes mellitus: what are the outcomes?}

The impacts of $\mathrm{BD}$ and diabetes mellitus on each other appear to be substantial. Recent work by Calkin et al. found that patients with $\mathrm{BD}$ and diabetes mellitus or insulin resistance had three times higher risk of having a chronic course of $\mathrm{BD}$ compared to euglycemic $\mathrm{BD}$ patients; patients with either type of insulin dysregulation also had three times higher risk of rapid cycling and were more likely to be refractory to lithium (Calkin et al. 2015). In a study of 82,060 patients with diabetes mellitus admitted to community hospitals over a 2-year period in Washington State, having a serious mental illness significantly increased the odds of rehospitalization for nonmental conditions within 1 month of discharge (odds ratio $1.24,95 \%$ confidence interval 1.07-1.44), even after controlling for demographics, medical co-morbidity, and index hospitalization (Chwastiak et al. 2014). Among the $2.2 \%$ with comorbid serious mental illness, $60 \%$ had a diagnosis of $\mathrm{BD}$, which was consistent with previous studies (Callaghan and Khizar 2010). Other studies confirmed that diabetes mellitus increased hospital-based mortality in patients with BD (Schoepf and Heun 2014; Sylvia et al. 2015).

Worryingly, BD and diabetes mellitus are each independently associated with increased risk of dementia and reduced cognitive performance (Biessels et al. 2006; Xu et al. 2009; Wu et al. 2013; Zilkens et al. 2014; Depp et al. 2014). After controlling for vascular risk factors, patients with diabetes mellitus show increased evidence for global brain atrophy relative to age- and gender-matched controls (Wisse et al. 2014; Biessels and Reijmer 2014), including reduced gray matter density, reduced cerebral glucose metabolism in frontotemporal regions (GarcíaCasares et al. 2014), increased ventricular volume (De Bresser et al. 2010), and white matter hyper-intensities (Reijmer et al. 2011). When compared to euglycemic BD patients and non-psychiatric controls, the BD patients with insulin resistance or glucose intolerance and diabetes mellitus had significantly more neurochemical changes in the prefrontal cortex, indicating reduced neuronal health (Hajek et al. 2015). In one study, patients with $\mathrm{BD}$ and diabetes mellitus or insulin resistance also had significantly smaller hippocampal and cortical volumes than either euglycemic BD patients or controls (Hajek et al. 2014).

Separately, each disease is associated with increased mortality. Diabetes mellitus is the seventh leading cause of death (Center for Disease Control 2014). Among adults 18 years and older during the years 2003-2006 in the US, a diagnosis of diabetes mellitus increased allcause mortality about 1.5 times over non-diabetics. For $\mathrm{BD}$, a Swedish national cohort study has shown that, relative to the general population, men and women with $\mathrm{BD}$ died on average 8.5 and 9.0 years earlier, respectively, and for each gender, having $\mathrm{BD}$ increased the risk of death by twofold (Crump et al. 2013). BD patients have a 20-fold greater risk of suicide relative to the general population (Jann 2014). Meanwhile, those with BD in addition to diabetes mellitus have increased mortality rates of 1.47 (95\% CI 1.07-2.02) versus those with diabetes mellitus but not BD (Vinogradova et al. 2010).

\section{Outlook}

\section{Investigations into treatment implications}

Both diabetes mellitus and BD are highly refractory: less than half of the participants in the National Health and Nutrition Examination Survey (NHANES) met glycemic control goals (Koro et al. 2004). BD patients in general have high rates of treatment non-adherence and 
recurrence. Furthermore, a strong association between HbA1c levels and symptoms of depression has been described in patients with BD (Bajor et al. 2015; Sajatovic et al. 2015b). Because of the difficulties in arresting progression of diabetes mellitus, achieving lifetime remission from BD, and the high stakes involved in both diseases, new treatment avenues, especially those that treat the potentially shared disease mechanisms of diabetes mellitus and $\mathrm{BD}$, are desirable.

In the search for new drug targets, glycogen synthase 3 (GSK-3) has taken center stage for its known involvement in several pathways linked to both BD and diabetes mellitus (Gould et al. 2004; Ronai et al. 2014; Huang et al. 2014; Iwahashi et al. 2014). In the rat, lithium, a standard treatment for $\mathrm{BD}$, reduces the enzyme's activity in the hippocampus and improves memory and learning $(\mathrm{Qu}$ et al. 2014). Novel GSK-3 inhibitors are now in preclinical testing (Datusalia and Sharma 2014; King et al. 2013).

In addition to the GSK-3 pathway, dysregulation of noradrenaline signaling could potentially be a shared disease mechanism between BD and diabetes mellitus, which has led to investigations into prophylactic use of noradrenaline modulators (Fitzgerald 2015). With the intention to target inflammatory pathways, toll-like receptor (TLR)-modifying agents have been tried in diabetes mellitus and BD among others (Ladefoged et al. 2013; McKernan et al. 2011; Lucas and Maes 2013). Last, but not least, treatment with the antidiabetic drug pioglitazone as an adjunct to lithium improved symptoms of depression in patients with BD even in the absence of diabetes mellitus (Zeinoddini et al. 2015).

\section{Bipolar disorder in the elderly: does age of onset hint a distinct disease phenotype?}

$\mathrm{BD}$ in the elderly poses specific challenges for diagnosis and treatment (Préville et al. 2008, 2010; Volkert et al. 2013; Sajatovic et al. 2015a). Although the usual gender ratio for $\mathrm{BD}$ is $1: 1$, in elderly patients, more women than men receive treatment for $\mathrm{BD}$. Lower overall cognitive and executive functioning have been reported in older patients with BD compared to both younger patients and normal controls in some studies (Tsai et al. 2009; Sheeran et al. 2012). However, not all studies have supported these conclusions (Delaloye et al. 2011). Age of onset of BD might be a confounding factor.

While BD usually presents with an age of onset during adolescence and early adulthood, some individuals experience a first episode of mania in and beyond the 5 th decade of life (Bellivier et al. 2001, 2003; Kennedy et al. 2005). Most studies on BD in the elderly have not distinguished between early-onset and late-onset cases, but the evidence for a separate subtype of BD distinguished by age of onset is growing, if complex. Late-onset mania appears to have a distinctive phenotype, pathophysiology, and risk factors (Leboyer et al. 2005; Vasudev and Thomas 2010; Sheeran et al. 2012; Schouws et al. 2009, 2012; Sajatovic et al. 2005; Sajatovic and Chen 2011; Sajatovic et al. 2015a). In several studies, the late-onset group differed in psychiatric comorbidities, including lower rates of lifetime alcohol and substance abuse, and lower rates of anxiety disorders. In some studies, elderly patients with late-onset BD performed particularly worse on tests of psychomotor function and mental flexibility compared to those with BD who had an earlier age of onset, though elderly patients with BD from both groups performed more poorly than age-matched controls (Schouws et al. 2009, 2012). An increasing burden of chronic health problems has been related to the risk of late-onset BD including diabetes mellitus, hyperlipidemia, and other cardiovascular conditions (Préville et al. 2010; Sylvia et al. 2015), whereas in BD individuals with younger age of onset the risk is much less.

Investigations into the relationship between $\mathrm{BD}$ and diabetes mellitus have generally focused on all ages of patients. Even though late-onset cases of BD were not explicitly excluded in most studies, we noticed that few studies clearly distinguished between early-onset and late-onset cases of BD. However, this distinction could be quite relevant to treatment and outcome. Reports that particularly focused on late-onset BD and diabetes mellitus were sparse, and large studies were non-existing.

\section{Gaps in knowledge and limitations of our study}

Even though diabetes mellitus and BD in the elderly are growing public health problems, clinical studies on these topics are sparse. In general, available studies still suffer from methodological problems including small sample size, limitations of retrospective chart review, lack of standardized measures, overemphasis on inpatients, and lack of longitudinal data. Several studies have addressed not only the increasing healthcare utilization in elderly patients with BD and medical comorbidity, pointing to a need for integrated medical and psychiatric care in this vulnerable population (Hendrie et al. 2013), but also to existing healthcare disparities for patients with mental illness (Gierisch et al. 2014; McGinty et al. 2015).

In our literature review, we have been unable to identify published large-scale, multi-center studies on the prevalence, the etiology, or the clinical features of late-onset BD. To our knowledge, no double-blind, randomized, controlled trials of pharmacologic treatments have been performed in this specific patient population. Therefore, we recommend to increase emphasis on research in BD during the late stages of the disease, which could inform about the disease course and risk factors across the lifespan. It is hoped that this knowledge will not only assist in 
enhancing services and improving outcomes, but it might also lead to the discovery of potentially new pathophysiological pathways and risk factors for BD and diabetes mellitus, as well as to novel treatments and interventions.

\section{Conclusions and recommendations}

Increasing evidence supports the association between $\mathrm{BD}$ and diabetes mellitus and suggests shared risk factors and disease mechanisms. This public health problem deserves focused attention, especially in the elderly, to improve diagnosis, treatment and outcome. A stronger integration of medical and psychiatric care could help prevent the negative effects of these co-occurring disorders on the long-term outcome of patients with BD. Therefore, we recommend to increase research efforts on late-life $\mathrm{BD}$ and diabetes mellitus to better understand the complex relationship that exists between these disorders. A better understanding of risk factors in BD and diabetes mellitus could lead to novel treatment approaches, early intervention and prevention.

\section{Abbreviations}

BD: bipolar disorder; DSM-IV: Diagnostic and Statistical Manual of Mental Disorders, 4th Edition; ICD: International Classification of Diseases; PPARY: peroxisome proliferator-activated receptor $\gamma$; CDK5: cyclin-dependent kinase 5; Thrap3: thyroid hormone receptor-associated protein 3; ER: endoplasmatic reticulum; GSK-3ß: glycogen synthase kinase-33; NHANES: National Health and Nutrition Examination Survey; TLR: toll-like receptor.
\end{abstract}

\section{Authors' contributions}

EFC and BK participated equally in the conception and design of the study. They selected and reviewed the literature and drafted the manuscript. CGL participated in the conception of the study and writing the manuscript. All authors read and approved the final manuscript.

\section{Author details \\ 1 David Geffen School of Medicine, University of California, Los Angeles, 10833 Le Conte Ave, Los Angeles, CA 90095, USA. ${ }^{2}$ Center for Global Health, Division of Translational Informatics, Department of Internal Medicine, University of New Mexico Health Sciences Center, University of New Mexico, MSC10 5550, Albuquerque, NM 87131, USA. ${ }^{3}$ Semel Institute for Neurosci- ence and Human Behavior, University of California, 695 Charles E. Young Drive South, Box 951761, Los Angeles, CA 90095, USA. ${ }^{4}$ Fakultät für Gesundheit, Private Universität Witten/Herdecke, Alfred-Herrhausen-Straße 50, 58448 Wit- ten, Germany.}

\section{Competing interests}

The authors declare that they have no competing interests.

\section{Ethical standards}

The authors assert that all procedures contributing to this work comply with the ethical standards of the relevant national and institutional committees on human experimentation and with the Helsinki Declaration of 1975, as revised in 2008.

\section{Financial support}

This research was not supported by any specific grant from any funding agency, commercial or not-for-profit sectors.

Received: 14 March 2016 Accepted: 18 May 2016

Published online: 07 July 2016

\section{References}

Alvarez Ariza M. Mateos Alvarez R, Berrios GE. A review of the natural course of bipolar disorders (manic-depressive psychosis) in the pre-drug era: review of studies prior to 1950. J Affect Disord. 2009;115:293-301.

American Psychiatric Association. Diagnostic and statistical manual of mental disorders. 5th ed. Arlington: American Psychiatric Association; 2013.

Bai YM, Su TP, Chen MH, Chen TJ, Chang WH. Risk of developing diabetes mellitus and hyperlipidemia among patients with bipolar disorder, major depressive disorder, and schizophrenia: a 10-year nationwide population-based prospective cohort study. J Affect Disord. 2013;150:57-62.

Bajor LA, Gunzler D, Einstadter D, Thomas C, McCormick R, Perzynski AT, et al. Associations between comorbid anxiety, diabetes control, and overall medical burden in patients with serious mental illness and diabetes. Int J Psychiatry Med. 2015;49:309-20.

Bauer M, Glenn T, Pilhatsch M, Pfennig A, Whybrow PC. Gender differences in thyroid system function: relevance to bipolar disorder and its treatment. Bipolar Disord. 2014;16:58-71.

Beers E, Moerkerken DC, Leufkens HG, Egberts TC, Jansen PA. Participation of older people in preauthorization trials of recently approved medicines. J Am Geriatr Soc. 2014;62:1883-90.

Bellivier F, Golmard JL, Henry C, Leboyer M, Schürhoff F. Admixture analysis of age at onset in bipolar I affective disorder. Arch Gen Psychiatry. 2001;58:510-2.

Bellivier F, Golmard JL, Rietschel M, Schulze TG, Malafosse A, Preisig M, et al. Age at onset in bipolar I affective disorder: further evidence for three subgroups. Am J Psychiatry. 2003;160:999-1001.

Biessels GJ, Reijmer YD. Brain changes underlying cognitive dysfunction in diabetes: what can we learn from MRI? Diabetes. 2014;63:2244-52.

Biessels GJ, Staekenborg S, Brunner E, Brayne C, Scheltens P. Risk of dementia in diabetes mellitus: a systematic review. Lancet Neurol. 2006;5:64-74.

Calkin CV, Gardner DM, Ransom T, Alda M. The relationship between bipolar disorder and type 2 diabetes: more than just co-morbid disorders. Ann Med. 2013:45:171-81.

Calkin CV, Ruzickova M, Uher R, Hajek T, Slaney CM, Garnham JS, et al. Insulin resistance and outcome in bipolar disorder. Br J Psychiatry. 2015;206:52-7.

Callaghan RC, Khizar A. The incidence of cardiovascular morbidity among patients with bipolar disorder: a population-based longitudinal study in Ontario, Canada. J Affect Disord. 2010;122:118-23.

Carliner H, Collins PY, Cabassa L, McNallen A, Joestl SS, Lewis-Fernández R. Prevalence of cardiovascular risk factors among racial and ethnic minorities with schizophrenia spectrum and bipolar disorders: a critical literature review. Compr Psychiatry. 2014;55:233-47.

Cassidy F, Ahearn E, Carroll BJ. Elevated frequency of diabetes mellitus in hospitalized manic-depressive patients. Am J Psychiatry. 1999;156:1417-20.

Center for Disease Control. National diabetes statistics report. 2014. http:// www.cdc.gov/diabetes/data/statistics/2014statisticsreport.html. Accessed 30 July 2015.

Chang YC, Chuang LM. The role of oxidative stress in the pathogenesis of type 2 diabetes: from molecular mechanism to clinical implication. Am J Trans Res. 2010;2:316-31.

Chen MH, Li CT, Lin WC, Wei HT, Chang WH, Chen TJ, et al. A predisposition for allergies predicts subsequent hypertension, dyslipidemia, and diabetes mellitus among patients with schizophrenia or bipolar disorder: a nationwide longitudinal study. Schizoph Res. 2014;159:171-5.

Chien IC, Chang KC, Lin CH, Chou YJ, Chou P. Prevalence of diabetes in patients with bipolar disorder in Taiwan: a population-based national health insurance study. Gen Hosp Psychiatry. 2010;32:577-82.

Choi JH, Choi SS, Kim ES, Jedrychowski MP, Yang YR, Jang HJ, et al. Thrap3 docks on phosphoserine 273 of PPARy and controls diabetic gene programming. Genes Dev. 2014;28:2361-9.

Chwastiak LA, Davydow DS, McKibbin CL, Schur E, Burley M, McDonell MG, et al. The effect of serious mental illness on the risk of rehospitalization among patients with diabetes. Psychosomatics. 2014;55:134-43.

Conn VS, Koopman RJ, Ruppar TM, Phillips LJ, Mehr DR, Hafdahl AR. Insulin sensitivity following exercise interventions: systematic review and meta-analysis of outcomes among healthy adults. J Prim Care Commun Health. 2014;5:211-22.

Correll CU, Detraux J, De Lepeleire J, De Hert M. Effects of antipsychotics, antidepressants and mood stabilizers on risk for physical diseases in people 
with schizophrenia, depression and bipolar disorder. World Psychiatry. 2015;14:119-36.

Crump C, Sundquist K, Winkleby MA, Sundquist J. Comorbidities and mortality in bipolar disorder: a Swedish national cohort study. JAMA Psychiatry. 2013;70:931-9.

Datusalia AK, Sharma SS. Amelioration of diabetes-induced cognitive deficits by GSK-3 $\beta$ inhibition is attributed to modulation of neurotransmitters and neuroinflammation. Mol Neurobiol. 2014;50:390-405.

Davydow DS, Ribe AR, Pedersen HS, Fenger-Grøn M, Cerimele JM, Vedsted P, et al. Serious mental illness and risk for hospitalizations and rehospitalizations for ambulatory care-sensitive conditions in Denmark: a nationwide population-based cohort study. Med Care. 2015;21:90.

De Bresser J, Tiehuis AM, van den Berg E, Reijmer YD, Jongen C, Kappelle LJ, et al. Progression of cerebral atrophy and white matter hyperintensities in patients with type 2 diabetes. Diabetes Care. 2010;33:1309-14.

Delaloye C, Moy G, De Bilbao F, Weber K, Baudois S, Haller S, et al. Longitudinal analysis of cognitive performances and structural brain changes in latelife bipolar disorder. Int J Geriat Psychiatry. 2011;26:1309-18.

Depp CA, Jeste DV. Bipolar disorder in older adults: a critical review. Bipolar Disord. 2004;6:343-67.

Depp CA, Strassnig M, Mausbach BT, Bowie CR, Wolyniec P, Thornquist MH, et al. Association of obesity and treated hypertension and diabetes with cognitive ability in bipolar disorder and schizophrenia. Bipolar Disord. 2014;16:422-31.

Dols A, Kupka RW, van Lammeren A, Beekman AT, Sajatovic M, Stek ML. The prevalence of late-life mania: a review. Bipolar Disord. 2014;16:113-8.

Esquirol JED. Mental maladies, a treatise on insanity. Philadelphia: Lea and Blanchard; 1845 . p. 1845.

Fagiolini A, Frank E, Scott JA, Turkin S, Kupfer DJ. Metabolic syndrome in bipolar disorder: findings from the bipolar disorder center for Pennsylvanians. Bipolar Disord. 2005;7:424-30.

Fitzgerald PJ. Noradrenaline transmission reducing drugs may protect against a broad range of diseases. Auton Autacoid Pharmacol. 2015;34:15-26.

Fleet-Michaliszyn SB, Soreca I, Otto AD, Jakicic JM, Fagiolini A, Kupfer DJ, et al. A prospective observational study of obesity, body composition, and insulin resistance in 18 women with bipolar disorder and 17 matched control subjects. J Clin Psychiatry. 2008;69:1892-900.

Foley DL, Mackinnon A, Morgan VA, Watts GF, Castle DJ, Waterreus A, et al. Effect of age, family history of diabetes, and antipsychotic drug treatment on risk of diabetes in people with psychosis: a population-based cross-sectional study. Lancet Psychiatry. 2015;2:1092-8.

García-Casares N, Berthier ML, Jorge RE, Gonzalez-Alegre P, Gutiérrez Cardo A, Rioja Villodres J, et al. Structural and functional brain changes in middle-aged type 2 diabetic patients: a cross-sectional study. J Alzheimers Dis. 2014;40:375-86.

García-Rizo C, Kirkpatrick B, Fernandez-Egea E, Oliveira C, Meseguer A, Grande I, et al. "Is bipolar disorder an endocrine condition?" Glucose abnormalities in bipolar disorder. Acta Psychiatr Scand. 2014;129:73-4.

Gierisch JM, Beadles C, Shapiro A, McDuffie JR, Cunningham N, Bradford D, et al. Health disparities in quality indicators of healthcare. Department of Veterans Affairs (US): Washington (DC); 2014

Goldstein BI, Kemp DE, Soczynska JK, Mcintyre RS. Inflammation and the phenomenology, pathophysiology, comorbidity, and treatment of bipolar disorder: a systematic review of the literature. J Clin Psychiatry. 2009:70:1078-90.

Goldstein BI, Liu SM, Zivkovic N, Schaffer A, Chien LC, Blanco C. The burden of obesity among adults with bipolar disorder in the United States. Bipolar Disord. 2011;13:387-95.

Gomes FA, Almeida KM, Magalhães PV, Caetano SC, Kauer-Sant'Anna M, Lafer $\mathrm{B}$, et al. Cardiovascular risk factors in outpatients with bipolar disorder: a report from the Brazilian research network in bipolar disorder. Rev Bras Psiquiatr. 2013;35:126-30.

Gould TD, Chen G, Manji HK. In vivo evidence in the brain for lithium inhibition of glycogen synthase kinase-3. Neuropsychopharmacology. 2004;29:32-8.

Guha P, Bhowmick K, Mazumder P, Ghosal M, Chakraborty I, Burman P. Assessment of insulin resistance and metabolic syndrome in drug naive patients of bipolar disorder. Indian J Clin Biochem. 2014;29:51-6.

Hajek T, Calkin C, Blagdon R, Slaney C, Alda M. Type 2 diabetes mellitus: a potentially modifiable risk factor for neurochemical brain changes in bipolar disorders. Biol Psychiatry. 2015;77:295-303.
Hajek T, Calkin C, Blagdon R, Slaney C, Uher R, Alda M. Insulin resistance, diabetes mellitus, and brain structure in bipolar disorders. Neuropsychopharmacology. 2014;39:2910-8.

Hamdani N, Doukhan R, Kurtlucan O, Tamouza R, Leboyer M. Immunity, inflammation, and bipolar disorder: diagnostic and therapeutic implications. Curr Psychiatry Rep. 2013;15:387.

Hendrie HC, Lindgren D, Hay DP, Lane KA, Gao S, Purnell C, et al. Comorbidity profile and healthcare utilization in elderly patients with serious mental illnesses. Am J Geriatr Psychiatry. 2013;21:1267-76.

Hsieh MH, Tang CH, Hsieh MH, Lee IH, Lai TJ, Lin YJ, et al. Medical costs and vasculometabolic comorbidities among patients with bipolar disorder in Taiwan a population-based and matched-control study. J Affect Disord. 2012;141:449-56.

Huang S, Zhu M, Wu W, Rashid A, Liang Y, Hou L, et al. Valproate pretreatment protects pancreatic $\beta$-cells from palmitate-induced ER stress and apoptosis by inhibiting glycogen synthase kinase-3ß. J Biomed Sci. 2014;21:38.

Iwahashi K, Nishizawa D, Narita S, Numajiri M, Murayama O, Yoshihara E, et al. Haplotype analysis of GSK-3 $\beta$ gene polymorphisms in bipolar disorder lithium responders and nonresponders. Clin Neuropharmacol. 2014;37:108-10.

Iwen KA, Schröder E, Brabant G. Thyroid hormones and the metabolic syndrome. Eur Thyroid J. 2013;2:83-92.

Jann MW. Diagnosis and treatment of bipolar disorders in adults: a review of the evidence on pharmacologic treatments. Am Health Drug Benefits. 2014:7:489-99.

Janney CA, Fagiolini A, Swartz HA, Jakicic JM, Holleman RG, Richardson CR. Are adults with bipolar disorder active? Objectively measured physical activity and sedentary behavior using accelerometry. J Affect Disord. 2014;152-154:498-504.

Janssen EM, McGinty EE, Azrin ST, Juliano-Bult D, Daumit GL. Review of the evidence: prevalence of medical conditions in the United States population with serious mental illness. Gen Hosp Psychiatry. 2015;37:199-222.

Kennedy N, Everitt B, Boydell J, Van Os J, Jones PB, Murray RM. Incidence and distribution of first-episode mania by age: results from a 35-year study. Psychol Med. 2005;35:855-63.

Kim HK, Chen W, Andreazza AC. The potential role of the NLRP3 inflammasome as a link between mitochondrial complex I dysfunction and inflammation in bipolar disorder. Neural Plast. 2015;2015:408136.

King MR, Anderson NJ, Guernsey LS, Jolivalt CG. Glycogen synthase kinase-3 inhibition prevents learning deficits in diabetic mice. J Neurosci Res. 2013;91:506-14.

Kodesh A, Goldshtein I, Gelkopf M, Goren I, Chodick G, Shalev V. Epidemiology and comorbidity of severe mental illnesses in the community: findings from a computerized mental health registry in a large Israeli health organization. Soc Psychiatry Psychiatr Epidemiol. 2012;47:1775-82.

Konz HW, Meesters PD, Paans NP, van Grootheest DS, Comijs HC, Stek ML, et al. Screening for metabolic syndrome in older patients with severe mental illness. Am J Geriat Psychiatry. 2014;22:1116-20.

Koro CE, Bowlin SJ, Bourgeois N, Fedder DO. Glycemic control from 1988 to 2000 among U.S. adults diagnosed with type 2 diabetes: a preliminary report. Diabetes Care. 2004;27:17-20.

Ladefoged M, Buschard K, Hansen AM. Increased expression of toll-like receptor 4 and inflammatory cytokines, interleukin-6 in particular, in islets from a mouse model of obesity and type 2 diabetes. APMIS. 2013;121:531-8.

Lala SV, Sajatovic M. Medical and psychiatric comorbidities among elderly individuals with bipolar disorder: a literature review. J Geriatr Psychiatry Neurol. 2012;25:20-5.

Leboyer M, Henry C, Paillere-Martinot ML, Bellivier F. Age at onset in bipolar affective disorders: a review. Bipolar Disord. 2005;7:111-8.

Leboyer M, Soreca I, Scott J, Frye M, Henry C, Tamouza R, et al. Can bipolar disorder be viewed as a multi-system inflammatory disease? J Affect Disord. 2012;141:1-10.

Li J, Sun X, Yu Y. The prevalence of impaired glucose regulation in psychiatric patients with sleep disorders and its relationship with altered hypothalamopituitary-adrenal and hypothalamopituitary-thyroid axis activity. Sleep Med. 2013;14:662-7. 
Lilliker SL. Prevalence of diabetes in a manic-depressive population. Compr Psychiatry. 1980;21:270-5.

Lucas K, Maes M. Role of the Toll Like receptor (TLR) radical cycle in chronic inflammation: possible treatments targeting the TLR4 pathway. Mol Neurobiol. 2013:48:190-204.

Maina G, Bechon E, Rigardetto S, Salvi V. General medical conditions are associated with delay to treatment in patients with bipolar disorder. Psychosomatics. 2013;54:437-42.

Maina G, Salvi V, Vitalucci A, D'ambrosio V, Bogetto F. Prevalence and correlates of overweight in drug-naïve patients with bipolar disorder. J Affect Disord. 2008:110:149-55.

McElroy SL, Kotwal R, Malhotra S, Nelson EB, Keck PE, Nemeroff CB. Are mood disorders and obesity related? A review for the mental health professional. J Clin Psychiatry. 2004;65:634-51.

McGinty EE, Baller J, Azrin ST, Juliano-Bult D, Daumit GL. Quality of medical care for persons with serious mental illness: a comprehensive review. Schizophr Res. 2015;165:227-35.

McIntyre RS, Konarski JZ, Misener VL, Kennedy SH. Bipolar disorder and diabetes mellitus: epidemiology, etiology, and treatment implications. Ann Clin Psychiatry. 2005;17:83-93.

McKernan DP, Dennison U, Gaszner G, Cryan JF, Dinan TG. Enhanced peripheral toll-like receptor responses in psychosis: further evidence of a proinflammatory phenotype. Transl Psychiatry. 2011;1:e36.

Merikangas KR, Akiskal HS, Angst J, Greenberg PE, Hirschfeld RM, Petukhova M, et al. Lifetime and 12-month prevalence of bipolar spectrum disorder in the national comorbidity survey replication. Arch Gen Psychiatry. 2007;64:543-52.

Merikangas KR, Jin R, He JP, Kessler RC, Lee S, Sampson NA, et al. Prevalence and correlates of bipolar spectrum disorder in the world mental health survey initiative. Arch Gen Psychiatry. 2011;68:241-51.

Perseghin G, Price TB, Petersen KF, Roden M, Cline GW, Gerow K, et al. Increased glucose transport-phosphorylation and muscle glycogen synthesis after exercise training in insulin-resistant subjects. N Engl J Med. 1996;335:1357-62.

Perugi G, Quaranta G, Belletti S, Casalini F, Mosti N, Toni C, et al. General medical conditions in 347 bipolar disorder patients: clinical correlates of metabolic and autoimmune-allergic diseases. J Affect Disord. 2015:170:95-103.

Préville M, Boyer R, Grenier S, Dubé M, Voyer P, Punti R, et al. The epidemiology of psychiatric disorders in Quebec's older adult population. Can J Psychiatry. 2008;53:822-32.

Préville M, Boyer R, Vasiliadis HM, Grenier S, Voyer P, Hudon C, et al. One-year incidence of psychiatric disorders in Quebec's older adult population. Can J Psychiatry. 2010;55:449-57.

Qu ZS, Li L, Sun XJ, Zhao YW, Zhang J, Geng Z, et al. Glycogen synthase kinase- 3 regulates production of amyloid- $\beta$ peptides and tau phosphorylation in diabetic rat brain. Sci World J. 2014;2014:878123.

Regenold WT, Thapar RK, Marano C, Gavirneni S, Kondapavuluru PV. Increased prevalence of type 2 diabetes mellitus among psychiatric inpatients with bipolar I affective and schizoaffective disorders independent of psychotropic drug use. J Affect Disord. 2002;70:19-26.

Reijmer YD, van den Berg E, de Bresser J, Kessels RP, Kappelle LJ, Algra A, et al. Accelerated cognitive decline in patients with type 2 diabetes: MRI correlates and risk factors. Diabetes/Metab Res Rev. 2011;27:195-202.

Reininghaus EZ, Zelzer S, Reininghaus B, Lackner N, Birner A, Bengesser SA, et al. Oxidativer Stress bei bipolar affektiver Störung [Oxidative stress in bipolar affective disorder]. Nervenarzt. 2014;85:1099-107.

Rennie T. Prognosis in manic-depressive psychoses. Am J Psychiatry. 1942:98:801-14.

Ronai Z, Kovacs-Nagy R, Szantai E, Elek Z, Sasvari-Szekely M, Faludi G, et al. Glycogen synthase kinase 3 beta gene structural variants as possible risk factors of bipolar depression. Am J Med Gen B Neuropsychiatr Genet. 2014;165B:217-22.

Rosenblat JD, McIntyre RS. Are medical comorbid conditions of bipolar disorder due to immune dysfunction? Acta Psychiatr Scand. 2015;132:180-91.

Ruzickova M, Slaney C, Garnham J, Alda M. Clinical features of bipolar disorder with and without comorbid diabetes mellitus. Can J Psychiatry. 2003:48:458-61.

Sajatovic M, Blow FC, Ignacio RV, Kales HC. New-onset bipolar disorder in later life. Am J Geriatr Psychiatry. 2005;13:282-9.
Sajatovic M, Chen P. Geriatric bipolar disorder. Psychiatr Clin North Am. 2011:34:319-33.

Sajatovic M, Strejilevich SA, Gildengers AG, Dols A, Al Jurdi RK, Forester BP, et al. A report on older-age bipolar disorder from the international society for bipolar disorders task force. Bipolar Disord. 2015a;17:689-704.

Sajatovic M, Gunzler D, Einstadter D, Thomas C, McCormick RA, Perzynski AT, et al. Clinical characteristics of individuals with serious mental illness and type 2 diabetes. Psychiatr Serv. 2015b;66:197-9.

Salvadore G, Viale Cl, Luckenbaugh DA, Zanatto VC, Portela LV, Souza DO, et al. Increased uric acid levels in drug-naïve subjects with bipolar disorder during a first manic episode. Prog Neuropsychopharmacol Biol Psychiatry. 2010;34:819-21.

Sami M, Khan H, Nilforooshan R. Late onset mania as an organic syndrome: a review of case reports in the literature. J Affect Disord. 2015;188:226-31.

Schoepf D, Heun R. Bipolar disorder and comorbidity: increased prevalence and increased relevance of comorbidity for hospital-based mortality during a 12.5-year observation period in general hospital admissions. J Affect Disord. 2014;169:170-8.

Schouws SN, Comijs HC, Stek ML, Dekker J, Oostervink F, Naarding P, et al. Cognitive impairment in early and late bipolar disorder. Am J Geriatr Psychiatry. 2009;17:508-15.

Schouws SN, Stek ML, Comijs HC, Dols A, Beekman AT. Cognitive decline in elderly bipolar disorder patients: a follow-up study. Bipolar Disord. 2012;14:749-55.

Sharma AN, Bauer IE, Sanches M, Galvez JF, Zunta-Soares GB, Quevedo J, et al. Common biological mechanisms between bipolar disorder and type 2 diabetes: focus on inflammation. Prog Neuropsychopharmacol Biol Psychiatry. 2014;54:289-98.

Sheeran T, Greenberg RL, Davan LA, Dealy JA, Young RC, Bruce ML. A descriptive study of older bipolar disorder residents living in New York City's adult congregate facilities. Bipolar Disord. 2012;14:756-63.

Smith DJ, Martin D, McLean G, Langan J, Guthrie B, Mercer SW. Multimorbidity in bipolar disorder and undertreatment of cardiovascular disease: a cross sectional study. BMC Med. 2013;11:263.

Stenstedt A. A study in manic-depressive psychosis; clinical, social and genetic investigations. Acta Psychiatr Neurol Scand. 1952;79:1-111.

Svendal G, Fasmer OB, Engeland A, Berk M, Lund A. Co-prescription of medication for bipolar disorder and diabetes mellitus: a nationwide population-based study with focus on gender differences. BMC Med. 2012:10:148.

Swift HM. The prognosis of recurrent insanity of the manic depressive type. Am J Psychiatry. 1907:64:311-26.

Sylvia LG, Shelton RC, Kemp DE, Bernstein EE, Friedman ES, Brody BD, et al. Medical burden in bipolar disorder: findings from the clinical and health outcomes initiative in comparative effectiveness for bipolar disorder study (bipolar choice). Bipolar Disord. 2015;17:212-23.

Thakurathi N, Henderson DC. Atypical antipsychotics are associated with incident diabetes in older adults without schizophrenia or bipolar disorder. Evid Based Ment Health. 2012;15:61.

Tsai SY, Kuo CJ, Chung KH, Huang YL, Lee HC, Chen CC. Cognitive dysfunction and medical morbidity in elderly outpatients with bipolar disorder. Am J Geriatr Psychiatry. 2009;17:1004-11.

Vancampfort D, Mitchell AJ, De Hert M, Sienaert P, Probst M, Buys R, et al. Prevalence and predictors of type 2 diabetes mellitus in people with bipolar disorder: a systematic review and meta-analysis. J Clin Psychiatry. 2015;76:1490-9.

Vasudev A, Thomas A. Bipolar disorder in the elderly: what's in a name? Maturitas. 2010;66:231-5

Vinogradova Y, Coupland C, Hippisley-cox J, Whyte S, Penny C. Effects of severe mental illness on survival of people with diabetes. Br J Psychiatry. 2010;197:272-7.

Volkert J, Schulz H, Härter M, Wlodarczyk O, Andreas S. The prevalence of mental disorders in older people in Western countries-a meta-analysis. Ageing Res Rev. 2013;12:339-53.

Wändell P, Ljunggren G, Wahlström L, Carlsson AC. Diabetes and psychiatric illness in the total population of Stockholm. J Psychosom Res. 2014;77:169-73.

Wang C. The relationship between type 2 diabetes mellitus and related thyroid diseases. J Diabetes Res. 2013;2013:390534. 
Wang X, Bao W, Liu J, Ouyang YY, Wang D, Rong S, et al. Inflammatory markers and risk of type 2 diabetes: a systematic review and meta-analysis. Diabetes Care. 2013;36:166-75.

Weston-Green K, Huang XF, Deng C. Second generation antipsychoticinduced type 2 diabetes: a role for the muscarinic M3 receptor. CNS Drugs. 2013;27:1069-80

Wisse LE, de Bresser J, Geerlings MI, Reijmer YD, Portegies ML, Brundel M, et al. Global brain atrophy but not hippocampal atrophy is related to type 2 diabetes. J Neurol Sci. 2014;344:32-6.

Wright E, Scism-Bacon JL, Glass LC. Oxidative stress in type 2 diabetes: the role of fasting and postprandial glycaemia. Int J Clin Pract. 2006;60:308-14.

Wu KY, Chang CM, Liang HY, Wu CS, Chia-Hsuan WuE, Chen CH, et al. Increased risk of developing dementia in patients with bipolar disorder: a nested matched case-control study. Bipolar Disord. 2013;15:787-94.
Wysokiński A, Strzelecki D, Kłoszewska I. Levels of triglycerides, cholesterol, LDL, HDL and glucose in patients with schizophrenia, unipolar depression and bipolar disorder. Diabetes Metab Syndr. 2015;9:168-76.

Xu W, Qiu C, Gatz M, Pedersen NL, Johansson B, Fratiglioni L. Mid- and late-life diabetes in relation to the risk of dementia: a population-based twin study. Diabetes. 2009;58:71-7.

Zeinoddini A, Sorayani M, Hassanzadeh E, Arbabi M, Farokhnia M, Salimi S, et al. Pioglitazone adjunctive therapy for depressive episode of bipolar disorder: a randomized, double-blind, placebo-controlled trial. Depress Anxiety. 2015;32:167-73.

Zilkens RR, Bruce DG, Duke J, Spilsbury K, Semmens JB. Severe psychiatric disorders in mid-life and risk of dementia in late-life (age 65-84 years): a population based case-control study. Curr Alzheimer Res. 2014;11:681-93.

\section{Submit your manuscript to a SpringerOpen ${ }^{\circ}$ journal and benefit from:}

- Convenient online submission

- Rigorous peer review

Immediate publication on acceptance

- Open access: articles freely available online

- High visibility within the field

- Retaining the copyright to your article 